\title{
Sonographic evaluation of maternal kidneys in normal pregnancy
}

Received: 30/3/2014

Accepted: 1/6/2014

\begin{tabular}{ccc}
\hline Shawnm Nasih Dawood * & Salwa Ahmed Amin * & Samira Salim ShekhMuhammed ** \\
\hline Abstract
\end{tabular}

Background and objective: Renal disease can affect the outcome of pregnancy. The renal system undergoes significant physiological and anatomical changes during pregnancy. Ultrasound is the commonest imaging modality used in the evaluation of the abdominal organs in pregnancy. The purpose of this study was to sonographically evaluate the kidneys in normal pregnancy.

Methods: A prospective descriptive study in which real time B-mode renal ultrasound was performed on 500 pregnant women attending for a routine obstetric ultrasound scan. Questions about the age, parity and presence of loin pain were asked. Obstetrical ultrasound examination was initially performed followed by examination of maternal kidneys.

Results: Renal collecting system dilatation was the main abnormal finding; it was present in $18.2 \%$ of cases, $(15.2 \%$ right side and $3 \%$ left side). Bilateral hydronephrosis was seen in $(2.6 \%)$ of cases. Rate of hydronephrosis was more in primiparous women. Other findings were renal stones $(2.8 \%$ right and $1.8 \%$ left sides, respectively), ureteric stone $(0.2 \%)$ and acute pyelonephritis (1\%).

Conclusion: This study established the value of renal sonography in the pregnant women, though not a common condition. Renal collecting system dilatation was the main finding. A significant proportion of patients with asymptomatic renal calculi were detected incidentally.

Keywords: Sonography, Maternal kidneys, Normal pregnancy, Hydronephrosis.

\section{Introduction}

The renal system undergoes significant physiological and anatomical changes during a normal pregnancy. ${ }^{1}$ The occurrence of hydronephrosis and hydroureters during pregnancy has been termed physiological. ${ }^{2}$ The dilatation develops during the second trimester, becomes more prominent on the right side and disappears within a few weeks after birth and is thought to be most pronounced in primigravid females. $^{1,3-5}$ The major risks are infection, renal failure, premature labor, and fetal death. ${ }^{6}$ Acute hydronephrosis or worsening of an existing hydronephrosis has been somewhat overlooked as a possible cause of uncertain abdominal pain during pregnancy. These conditions are examined by means of ultrasonography and treated by a change in position. In cases of continued pain or affected renal function, the treatment is insertion of a ureteral pigtail catheter. ${ }^{7,8}$ Urolithiasis in pregnancy is rare, but is a significant pathology. Any metabolic effects and the anatomical changes happen in pregnancy can have important role on stone formation. ${ }^{9}$ Approximately 1 per 1500 pregnancies is complicated by urinary calculi. The prevalence of ureteric calculi in pregnancy is low and is estimated around $0.03-0.4 \%$ depending on the population. ${ }^{1,4}$ Most pregnant women with renal colic present in the second half of pregnancy with flank pain or hematuria. ${ }^{4}$ Maternal kidney stones are significantly associated with several pregnancy complications. ${ }^{10,11}$ All forms of treatment with the exception of

* Department of surgery, college of medicine, Hawler medical university, Erbil, Iraq.

** Erbil maternity hospital, Erbil, Iraq. 
extracorporeal shock wave lithotripsy are appropriate in the pregnant patients. ${ }^{12}$ Acute pyelonephritis affects $1-2 \%$ of pregnant women and this can result in premature labor in $20-30 \%$ of women. These premature infants are at high risk of neonatal death in resource-limited settings. ${ }^{13}$ Sonography is typically negative, but findings such as renal enlargement, focal hyperechogenicity, and perinephric fluid may be present. ${ }^{4}$ Maternal renal disease, especially if associated with hypertension, not only adversely affects maternal health and increases fetal morbidity and mortality but may also program the fetus for renal disease and hypertension in adult life. ${ }^{14,15}$ Sonography is the initial imaging study of choice in the evaluation of the kidneys of the pregnant women, in whom ionizing radiation must be kept to a minimum. It can be used at any stage of the pregnancy. It is a relatively inexpensive and versatile technique that is readily available. ${ }^{16}$ The aim of this study was to show the role of diagnostic sonography in delineating various renal conditions occurring during pregnancy.

\section{Methods}

This is a prospective, descriptive study involving collection of data from daily ultrasound clinic in Erbil city, Kurdistan region of Iraq, from September 2011 till March 2012. The study sample included pregnant women attending routine obstetric ultrasound examination. A sample of 500 pregnant women participated in the study. Data about age, parity and history of lion pain were obtained. No particular attention was paid to the state of the bladder as long as the subjects were felt comfortable and not over-distended. Obstetrical ultrasound was performed for all participants in supine position and then turned to decubitus position for renal examination. The right kidney was scanned first through the left lateral decubitus position by scanning through the posterior axillary line intercostally or subcostally, while the left kidney was scanned through the right lateral decubitus position by scanning through the posterior axillary line or subcostally. The liver was used as an acoustic window on the right, while the spleen was used on the left. Images of each kidney were obtained in the coronal plane of the kidney, clearly identified as were outlined by the brightlyechogenic renal capsule with a central (sinus) echogenicity, images were frame-frozen and evaluated regarding renal morphology, state of pelvi-calyceal system whether dilated or not, presence of renal or ureteric stones. Degree of hydronephrosis was based on maximum calyceal diameter when $\leq 5 \mathrm{~mm}$ indicating no pelvicalyceal dilatation, mild $(6-10 \mathrm{~mm})$ moderate $(11-15 \mathrm{~mm})$ and severe $(>15 \mathrm{~mm})$ sinus echo separation, respectively. ${ }^{16} A$ urinary stone can be diagnosed on sonography when there is distinct focal echogenicity with discrete acoustic shadowing. ${ }^{4}$ In suspected cases of pyelonephritis ultrasound findings were supported by laboratory examinations such as general urine examination and urine culture. Real time, B mode, grey scale ultrasound examination was done by using U/S machines (MEDISON, ACCUVIX V20 and GE VOLUSON S8) which were fitted with a $3.5 \mathrm{MHz}$ transducer. The study was approved by the Research Ethics Committee of the College of Medicine in Hawler Medical University. Informed consent was obtained from all participants. Statistical package for the social sciences (version 21.0) was used for data entry and analysis. Both descriptive and analytic approaches were used; descriptive to determine the frequencies, mean and standard deviation; and analytic by using Chi-square test to find out associations. A P value $\leq 0.05$ was regarded statistically significant.

\section{Results}

Of 500 pregnant women, 184 (36.8\%) were primigravida and $316(63.2 \%)$ were multigravida; $166(33.2 \%)$ were in their first trimester, $192(38.4 \%)$ in second trimester and $142(28.4 \%)$ in third trimester 
pregnancy. The age range of the pregnant women was $15-44$ years with mean $( \pm S D)$ of $27.2 \pm 5$ years. The overall renal conditions detected by sonography were collecting system dilatation (physiological hydronephrosis), renal stones, ureteric stone and pyelonephritis. Physiological hydronephrosis was the main finding (Figure 1). There was a statistically significant association between hydronephrosis and the gestational ages of the pregnant women as the rate of hydronephrosis (right and left) increased with advancing gestational age $(P=0.001$ and 0.004, respectively). Bilateral hydronephrosis was seen in 13 out of 500 pregnant women $2.6 \%)$. Hydronephrosis was more common (in primigravida (17.4\%) than multigravid women $(13.9 \%)$ but this difference was not statistically significant (Table1).

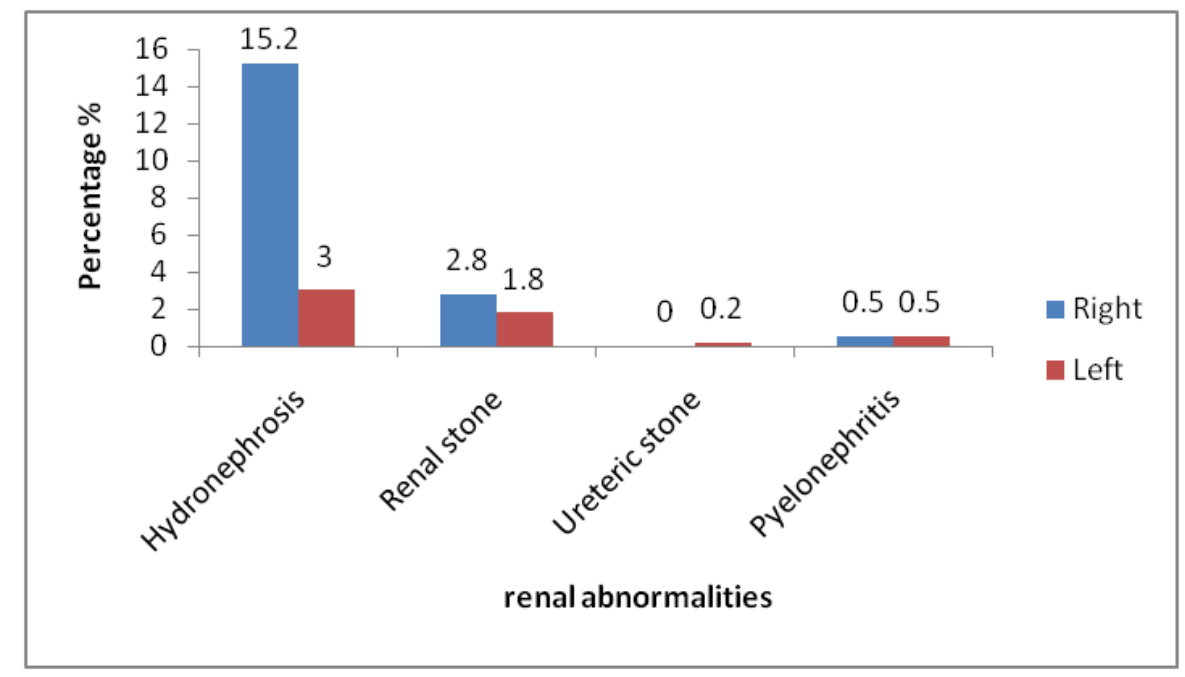

Figure 1: Percentages of abnormal sonographic findings among the studied sample.

Table 1: Association between hydronephrosis with gestational ages and parity.

\begin{tabular}{|c|c|c|c|c|c|c|c|c|}
\hline \multirow{3}{*}{ Variables } & & \multirow{3}{*}{ No. } & \multicolumn{4}{|c|}{ Hydronephrosis } & \multirow{2}{*}{\multicolumn{2}{|c|}{ Bilateral }} \\
\hline & & & Right & & Left & & & \\
\hline & & & No. & $\%$ & No. & $\%$ & No. & $\%$ \\
\hline \multirow[t]{4}{*}{ Gestational age } & $1^{\text {st }}$ Trimester & 166 & 13 & 7.8 & 2 & 1.2 & 1 & 0.6 \\
\hline & $2^{\text {nd }}$ Trimester & 192 & 30 & 15.6 & 3 & 1.6 & 2 & 1.0 \\
\hline & $3^{\text {rd }}$ Trimester & 142 & 33 & 23.2 & 10 & 7.0 & 10 & 7.0 \\
\hline & Total & 500 & 76 & 15.2 & 15 & 3.0 & 13 & 2.6 \\
\hline $\mathrm{p}$ & & & \multicolumn{2}{|l|}{0.001} & \multicolumn{2}{|l|}{0.004} & & \\
\hline \multirow[t]{3}{*}{ Parity } & Multi & 316 & 44 & 13.9 & 9 & 2.8 & & \\
\hline & Primi & 184 & 32 & 17.4 & 6 & 3.3 & & \\
\hline & Total & 500 & 76 & 15.2 & 15 & 3.0 & & \\
\hline $\mathrm{p}$ & & & \multicolumn{2}{|l|}{0.298} & \multicolumn{2}{|l|}{0.794} & & \\
\hline
\end{tabular}


Significant association was found between renal pain (right and left) and hydronephrosis (right and left) $P<0.001$ for both (Table 2). Regarding association between trimester of pregnancy and severity of calyceal dilatation or hydronephrosis; there was no significant association between gestational age and the severity of right side hydronephrosis, while there was a significant association between severity of left side hydronephrosis and gestational ages of the pregnant women, $p$ value- 0.031 (Table 3 ). This study also showed significant association between renal stone (right and left) and renal pain (right and left), $\mathrm{P}<0.001$ for both (Table 4).

Table 2: Association between renal pain and hydronephrosis.

\begin{tabular}{|c|c|c|c|c|c|c|}
\hline \multirow{3}{*}{ Right Renal pain } & \multicolumn{6}{|c|}{ Right Hydronephrosis } \\
\hline & \multicolumn{2}{|c|}{ Yes } & \multicolumn{2}{|l|}{ No } & \multicolumn{2}{|c|}{ Total } \\
\hline & No. & $\%$ & No. & $\%$ & No & $\%$ \\
\hline Yes & 67 & 88.2 & 9 & 11.8 & 76 & 100 \\
\hline No & 75 & 17.7 & 349 & 82.3 & 424 & 100 \\
\hline Total & 142 & 28.4 & 358 & 71.6 & 500 & 100 \\
\hline \multirow[t]{2}{*}{$\mathrm{p}$} & \multicolumn{6}{|c|}{$<0.001$} \\
\hline & \multicolumn{6}{|c|}{ Left Hydronephrosis } \\
\hline \multirow[t]{2}{*}{ Left Renal pain } & Yes & & No & & Total & \\
\hline & No. & $\%$ & No. & $\%$ & No. & $\%$ \\
\hline Yes & 10 & 66.7 & 5 & 33.3 & 59 & 100 \\
\hline No & 49 & 10.1 & 436 & 89.9 & 441 & 100 \\
\hline Total & 59 & 11.8 & 424 & 88.2 & 500 & 100 \\
\hline $\mathrm{p}$ & \multicolumn{6}{|c|}{$<0.001$} \\
\hline
\end{tabular}

Table 3: Association between gestational age and severity of hydronephrosis.

\begin{tabular}{|c|c|c|c|c|c|c|c|c|c|c|c|c|}
\hline \multirow[t]{4}{*}{ Gestational age } & \multicolumn{12}{|c|}{ Severity of hydronephrosis } \\
\hline & \multicolumn{6}{|c|}{ Right hydronephrosis } & \multicolumn{6}{|c|}{ Left hydronephrosis } \\
\hline & \multicolumn{2}{|c|}{ Mild } & \multicolumn{2}{|c|}{ Moderate } & \multicolumn{2}{|c|}{ Total } & \multicolumn{2}{|c|}{ Mild } & \multicolumn{2}{|c|}{ Moderate } & \multicolumn{2}{|c|}{ Total } \\
\hline & No. & $\%$ & No. & $\%$ & No. & $\%$ & No. & $\%$ & No. & $\%$ & No. & $\%$ \\
\hline $1^{\text {st }}$ Trimester & 11 & 84.6 & 2 & 15.4 & 13 & 100 & 1 & 50 & 1 & 50 & 2 & 100 \\
\hline $2^{\text {nd }}$ Trimester & 24 & 80.0 & 6 & 20.0 & 30 & 100 & 3 & 100 & 0 & 0.0 & 3 & 100 \\
\hline $3^{\text {rd }}$ Trimester & 25 & 75.8 & 8 & 24.2 & 33 & 100 & 10 & 100 & 0 & 0.0 & 10 & 100 \\
\hline Total & 60 & 78.9 & 16 & 21.2 & 76 & 100 & 14 & 93.3 & 1 & 6.7 & 15 & 100 \\
\hline $\mathrm{p}$ & 0.46 & & & & & & 0.03 & & & & & \\
\hline
\end{tabular}

Table 4: Association between renal stone and renal pain.

\begin{tabular}{|c|c|c|c|c|c|c|}
\hline \multirow{3}{*}{ Right Renal pain } & \multicolumn{4}{|c|}{ Right Renal Stone } & \multirow{2}{*}{\multicolumn{2}{|c|}{ Total }} \\
\hline & Yes & & No & & & \\
\hline & No. & $\%$ & No. & $\%$ & No. & $\%$ \\
\hline Yes & 10 & 7.0 & 132 & 93.0 & 142 & 100 \\
\hline No & 4 & 1.1 & 354 & 98.9 & 358 & 100 \\
\hline Total & 14 & 2.8 & 486 & 97.2 & 500 & 100 \\
\hline \multirow[t]{2}{*}{$\mathrm{p}$} & \multicolumn{6}{|c|}{$<0.001$} \\
\hline & \multicolumn{6}{|c|}{ Left Renal stone } \\
\hline \multirow[t]{2}{*}{ Left Renal pain } & Yes & & No & & Total & \\
\hline & No. & $\%$ & No. & $\%$ & No. & $\%$ \\
\hline Yes & 6 & 10.2 & 53 & 89.8 & 59 & 100 \\
\hline No & 3 & 0.7 & 438 & 99.3 & 441 & 100 \\
\hline Total & 9 & 1.8 & 491 & 98.2 & 500 & 100 \\
\hline $\mathrm{p}$ & \multicolumn{6}{|c|}{$<0.001$} \\
\hline
\end{tabular}




\section{Discussion}

This study showed that the major abnormal finding was renal collecting system dilatation (hydronephrosis). This develops as a result of compression of the ureter by the gravid uterus and the pelvic brim and progesterone-mediated relaxation of the urinary tract smooth muscle. ${ }^{4}$ There is no information available regarding the maternal hydronephrosis in our population. The overall incidence of hydronephrosis was $15.2 \%$ for the right side and $3 \%$ for the left side and these figures are very much less than that stated in a literature survey done by Rasmussen and Nielsen. ${ }^{3}$ Siyal et $\mathrm{al}^{18}$ evaluated maternal kidneys after 30 weeks gestation and found physiologic hydronephrosis in $64.2 \%$ of the examined pregnant women. Regarding right predominance of hydronephrosis in pregnancy, our study is in agreement of several early studies. ${ }^{3-6,16,17}$ The right sided predominance has been attributed to the differences in the anatomical relations of the right and left ureters. ${ }^{17,18}$ Results of no occurrence of hydronephrosis in 424 out of $500(84.8 \%)$ for the right kidney and 485 out of $500(97 \%)$ for the left kidney is higher than detected by Enighe et $\mathrm{al}^{16}$ that showed $54.3 \%$ for the right and $88.6 \%$ for the left kidneys in pregnant women. Bilateral hydronephrosis was found in $2.6 \%$ of cases and it was more severe on the right side than on the left nearly same as found by Faundes et al. ${ }^{5}$ Though statistically non-significant; this study showed higher rate of gestational hydronephrosis in primigravia women and this is in agreement with other studies. ${ }^{1,3,5}$ Our study showed statistically significant association between renal pain and hydronephrosis both for the right and left sides, right hydronephrosis was seen in $17.7 \%$ of asymptomatic pregnant women while The and Chan found $9 \%{ }^{6}$ The present study revealed that hydronephrosis can be seen in either trimester of pregnancy but it was more in occurrence and severity in second and third trimesters. Other studies state that gestational hydronephrosis occur in second trimester and remain the same in third trimester. ${ }^{5,6}$ All cases of hydronephrosis were either mild or moderate, there were no cases of severe hydronephrosis and this is in agreement with Karabulutet $\mathrm{al}^{17}$ and Siyal et al. ${ }^{18}$ Presence of renal stone in our study was $2.8 \%$ for the right kidney and $1.8 \%$ for the left kidney and this is higher than that stated by Glanc and Maxwell. ${ }^{4}$ Presence of ureteric stone was $0.2 \%$, which is in agreement with Weerakkody ${ }^{1}$ that reported $0.03 \%-0.4 \%$. A significant proportion of patients with asymptomatic renal calculi were detected incidentally. The potential hazards of intervention (either surgical or medical) and anesthesia need to be considered carefully. ${ }^{9}$ The incidence of acute pyelonephritis was $1 \%$, all in the second trimester. This is in agreement with Sharma and Thapa ${ }^{19}$ that found $1.3 \%$ and Bajwa et $\mathrm{al}^{20}$ that found $1-2 \%$.

\section{Conclusion}

The method of ultrasonography used in the assessment of maternal kidneys was easy, non-invasive and reliable one. Given the close proximity of the urinary system to the uterus and adnexa, it is not surprising that renal examination can result in the discovery of incidental findings. Renal collecting system dilatation was the major finding detected by ultrasound and it was more on the right side.

\section{Conflicts of interest}

The author reports no conflicts of interest.

Acknowledgment; The authors would like to thank professor Namir Ghanim Al Tawil (FICMS/CM) and Dr. Samir Othman (PhD/CM) from Community Medicine Department/College of Medicine/ Hawler medical university for their valuable help in statistical analysis.

\section{References}

1. Weerakkod Y. Maternal hydronephrosis in pregnancy. Available from: http:// www.imagingpathways.health.wa.gov.au. Accessed at Feb. 2014. 
2. Edgar VL, Jeffery SB, Allen RN. Current diagnosis and treatment: Nephrology and hypertension. Chapter 55. Pregnancy and renal disease. USA: McGraw Hill Companies; 2009.

3. Rasmussen PE, Nielsen FR. Hydronephrosis during pregnancy: a literature survey. Eur J Obstet Gynecol Reprod Biol 1988; 27(3):249-59.

4. Glanc P, Maxwell C. Acute Abdomen in Pregnancy: role of Sonography. J Ultrasound Med 2010; 29:1457-68.

5. Faundes A, Bricola-Filho M, Pinto e Silva JL. Dilatation of the urinary tract during pregnancy: proposal of a curve of maximal caliceal diameter by gestational age. Am J Obstet Gynecol 1998; 178:1082-6.

6. The S, Chan L. Pelvicalyceal dilatation in maternal kidneys during normal pregnancy-an uncommon finding?. Ultrasound ObstetGynecol 2007; 30 (4):529.

7. Puskar D, Balagović I, Filipović A. Symptomatic physiologic hydronephrosis in pregnancy: incidence, complications and treatment. EurUrol 2001; 39(3):260-3.

8. Fainaru O, Almog B, Gamzu R. The management of symptomatic hydronephrosis in pregnancy. BJOG 2002; 109(12):1385-7.

9. Srirangam SJ, Hickerton B, Van Cleynenbreugel $B$. Management of urinary calculi in pregnancy: a review. J Endourol 2008; 22(5):867-75.

10. Proia L, Lippa A, Valente A. Review on renal calculosis in pregnancy. ClinTer 1997; 148 (12):667-73.

11. Rosenberg E, Sergienko R, Abu-Ghanem S. Nephrolithiasis during pregnancy: characteristics, complications, and pregnancy outcome. World $\mathrm{J}$ Urol 2011; 29(6):743-7.

12. Travassos M, Amselem I, Filho NS, Miguel $M$, Ureteroscopy in pregnant women for ureteral stone. J Endourol 2009; 23(3):405-7.

13. McGready R1, Wuthiekanun V, Ashley EA, Tan SO, Pimanpanarak M, Viladpai-Nguen SJ. Diagnostic and treatment difficulties of pyelonephritis in pregnancy in resource-limited settings. Am J Trop Med Hyg 2010; 83(6):1322-9.

14. Gibson KJ , Thomson CL , Boyce AC , Karime $B M$, Eugenie R. Effects of a reduction in maternal renal mass on pregnancy and cardiovascular and renal function of the pregnant ewe. Am J Physiol Renal Physiol 2006; 290:1153-62.

15. Huxley RR, Shiell AW, Law CM. The role of size at birth and postnatal catch-up growth in determining systolic blood pressure: a systematic review of the literature. J Hypertens 2000; 18:815-31.

16. Enighe W, Henry A, Nelson C, Antony O, Ugboma. Sonographic Evaluation of the renal volume in normal pregnancy at the University of Port Harcourt Teaching Hospital: A Pilot Study. J Clin Diagn Res 2012; 6(2):234-8.

17. Karabulut N, BakiYağci A, Karabulut A. Renal vein Doppler ultrasound of maternal kidneys in normal second and third trimester pregnancy. Brit J Radiol 2003; 76:444-7.

18. Siyal A, Abbasi A, ShaikhSh, Shaikh FA. Maternal hydronephrosis in pregnancy: ultrasonic evaluation after 30 weeks of gestation. Med channel J. 2010; 16(4). Available from: http://www.medicalchannel.pk/past-issues/html\% 3Fstart\%3D10. Accessed at Feb. 2014

19. Sharma $P$, Thapa L. Acute pyelonephritis in pregnancy: a retrospective study. Aust $\mathrm{N} \mathrm{Z} \mathrm{J}$ Obstet Gynaecol 2007; 47(4):313-5.

20. Bajwa SJS, Kwatra IS, Bajwa SK, Kaur M. Renal diseases during pregnancy: Critical and current perspectives. J Obstet Anaesth Crit Care2013; 3:7-15. 